NASA Technical Memorandum 106283

$1 N-20$

AIAA-93-2217

\title{
Characterization of In-Flight Performance of Ion Propulsion Systems
}

(NASA-TM-106283) CHARACTERIZATION OF IN-FLIGHT PERFORMANCE OF ION PROPULSION SYSTEMS (NASA) $15 \mathrm{p}$
N94-10761

Unclas

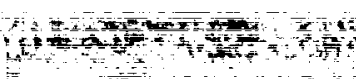



$63 / 20 \quad 0185027$

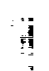

James S. Sovey and Vincent K. Rawlin

Lewis Research Center

Cleveland, Ohio

Prepared for the

29th AIAA Joint Propulsion Conference and Exhibit cosponsored by the AJAA, SAE, ASME and ASEE

Monterey, California, June 28-30, 1993 


\title{
Characterization of In-Flight Performance of Ion Propulsion Systems
}

\author{
James S. Sovey* and Vincent K. Rawlin* \\ National Aeronautics and Space Administration \\ Lewis Research Center \\ Cleveland, Ohio 44135
}

\begin{abstract}
In-flight measurements of ion propulsion performance, ground test calibrations, and diagnostic performance measurements were reviewed. It was found that accelerometers provided the most accurate in-flight thrust measurements compared with four other methods that were surveyed. An experiment has also demonstrated that pre-flight alignment of the thrust vector was sufficiently accurate so that gimbal adjustments and use of attitude control thrusters were not required to counter disturbance torques caused by thrust vector misalignment. The effects of facility background pressure, facility enhanced charge-exchange reactions, and contamination on ground-based performance measurements are also discussed. Vacuum facility pressures for Inert-gas ion thruster life tests and fight qualification tests will have to be less than $2 \mathrm{mPa}$ to ensure accurate performance measurements.
\end{abstract}

Nomenclature

$$
\begin{aligned}
& \mathrm{A}_{\mathrm{G}} \quad=\text { negative grid open area, } \mathrm{m}^{2} \\
& \text { a } \quad=\text { acceleration of spacecraft, } \mathrm{m} / \mathrm{s}^{2} \\
& \mathrm{~d}=\text { distance of accelerometer from spacecraft } \\
& \text { center-of-mass, } \mathrm{m} \\
& \text { e = electronic charge, } 1.6 \times 10^{-19} \mathrm{C} \\
& \mathrm{F} \quad=\text { thrust, } \mathrm{N} \\
& \mathrm{F}_{\mathrm{T}} \quad=\text { thrust correction factor for ion beam } \\
& \text { divergence } \\
& F_{\text {TAN }}=\text { tangential thrust, } \mathrm{N} \\
& \Delta \mathrm{f} \quad=\text { net frequency of spacecraft rotation due to } \\
& \text { the ion thruster, } s^{-1} \\
& \text { g = Earth gravitational acceleration, } 9.81 \mathrm{~m} / \mathrm{s}^{2} \\
& \mathrm{I}_{\mathrm{RW}} \quad=\text { moment of inertia of reaction wheel, } \mathrm{kg} \mathrm{\textrm {m } ^ { 2 }} \\
& \mathrm{I}_{\mathrm{SA}} \quad=\text { moment of inertia about spacecraft spin } \\
& \text { axis, } \mathrm{kg} \mathrm{m} \mathrm{m}^{2} \\
& I_{y y}=\text { moment of inertia about the pitch axis, } \mathrm{kg} \\
& \mathrm{m}^{2} \text { (See Figure 5) } \\
& \mathrm{J}_{\mathrm{B}} \quad=\text { ion beam current, } \mathrm{A}
\end{aligned}
$$

\footnotetext{
"Copyright (9) 1993 by the American Institute of Aeronautics and Astronautics, Inc. No copyright is asserted in the United States under Title 17, U.S. Code. The U.S. Government has a royalty-free license to exercise all rights under the copyright claimed herein for Government purposes. All other rights are reserved by the copyright owner."

* Aerospace Engineer, Space Propulsion Technology Division. AIAA Member
}

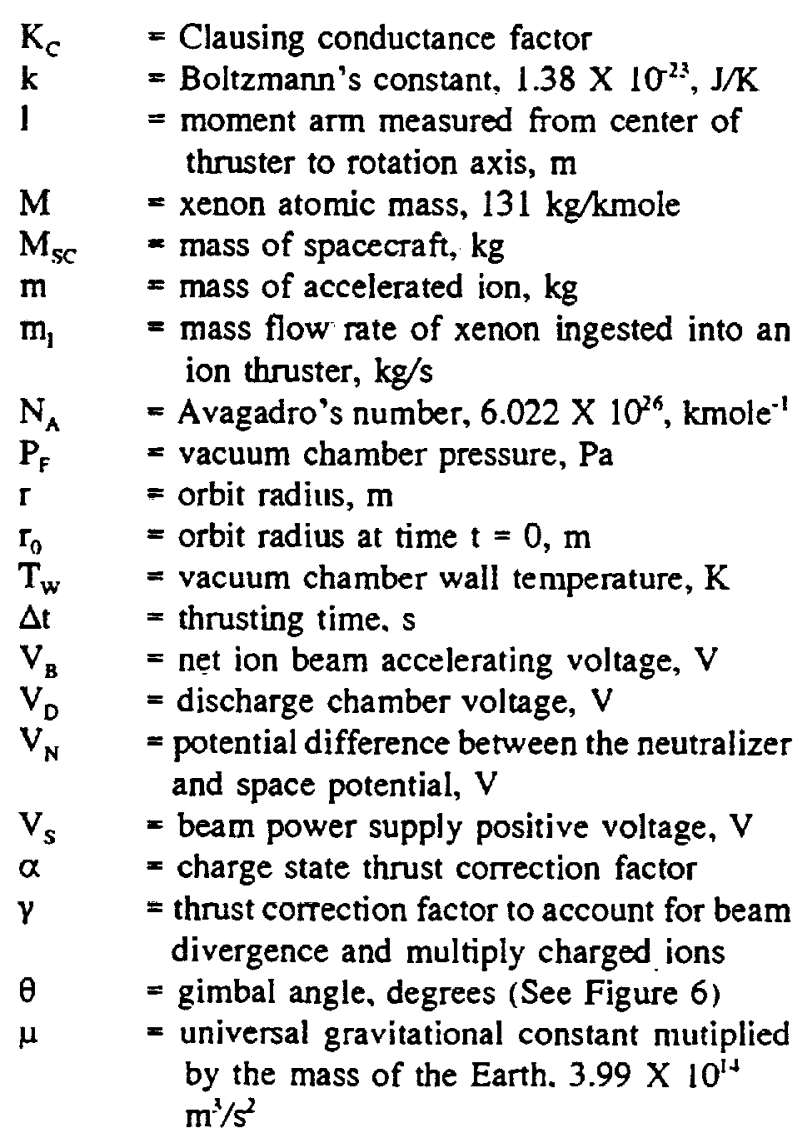




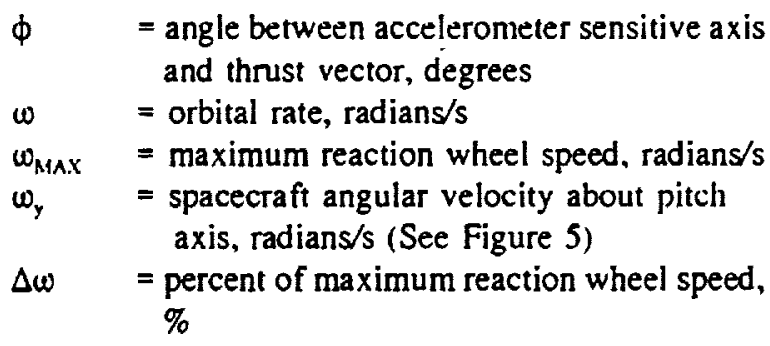

\section{Introduction}

By the mid-1990's nine spacecraft will have flown ion propulsion systems. ${ }^{1-3}$ The ion propulsion systems either provided stationkeeping and orbit adjustment or were experiments. Ion thruster flights have verified the thruster performance was the same as ground test results, provided operational experience, verified beam neutralization, confirmed structural integrity, and validated compatibility with other spacecraft systems. The past experiences have also provided a large data base on thrust subsystem operating characterisitics, component life, and interactions of the thrusters with spacecraft system functions. ${ }^{1,4}$ Although there is a large data base of ion propulsion flight experiences, a summary of in-flight performance measurements as they might apply to present generation inert-gas ion thruster systems has not been undertaken. Development approaches to new flight systems could benefit from experiences with diagnostic systems previously used and also from knowledge gained conceming the differences experienced in ground and flight testing of ion propulsion systems. Kerslake and Ignaczak ${ }^{4}$ recently reviewed the Space Electric Rocket Test II (SERT II) ion thruster flight. Thruster performance and operational experiences, results of probe diagnostics, contamination experiments, and performance of spacecraft systems were summarized. In-flight diagnostics have also been reported for other mercury" and cesium ${ }^{6}$ ion thrusters. A significant amount of information has also been reported on ion thruster system particle and field interactions in ground and flight tests. ${ }^{78}$

This paper focuses on a review of in-flight system performance, ground test calibrations, and diagnostic performance measurements used on spacecraft employing ion thrusters. Also discussed are groundbased performance measurement limitations due to effects of background pressure on thruster performance, facility enhanced propellant charge-exchange interactions, and contamination of electrodes.

\section{Performance Measurements}

The review of ion propulsion system performance measurements will focus on in-flight thrust measurements, thrust vector determinations, and mass flowrate measurement methods. Much of the in-flight thrust measurement experience was obtained from SERT $U^{4}$ and Japan's Engineering Test Satellite III (ETS III)."

\section{Thrust Measurements}

Thrust Measurements From Electrical Parameters. - The thrust level of ion thrusters can be determined in flight from telemetered parameters by using ion beam divergence and charge-state thrust correction factors obtained from ground-based thrust stand data. Depending on the operating condition, between $8 \%$ and $15 \%$ of the propellant is ejected at thermal speeds and contributes less than $0.1 \%$ to the thrust. If the discharge chamber cathode is electrically referenced to the positive ion extraction power supply voltage, the thrust can be computed from:

$$
F=\gamma J_{B}\left(2 V_{B} m / e\right)^{1 / 2},
$$

where

$$
V_{B} \approx V_{S}+V_{D}-\left|V_{N}\right|,
$$

and

$$
\gamma=\alpha F_{T} .
$$

The ion beam current and the voltages $V_{D}$ and $V_{S}$ can be telemetered, and $\gamma$ can be determined from ground thrust measurements., ${ }^{9,10}$ The value of $F_{T}$ can be determined from ground-based beam probe data. ${ }^{0.12}$ The neutralizer potential relative to space plasma potential, $V_{N}$, will have to be determined from local electrostatic probe measurements. The preferred method of obtaining in-flight thrust measurements from electrical parameters includes ground-based thrust stand measurements to determine the thrust correction factor, $\gamma$, and use of telemetered values of $J_{B}, V_{S}, V_{D}$, and $V_{N}$ for input to Equations ( 1 ) and (2). Unfortunately, this method must rely on ground-based 
measurements of $\gamma$. The validity of this procedure will be discussed when the thrust determined by Equation ( 1 ) is compared to the thrust obtained from in-flight accelerometer measurements. The spacebased performance measurements can be compared to ground-based thrust measurements and ion beam diagnostics.

Schematics of representative thrust-stands ${ }^{9,10}$ are shown in Figures 1 and 2. One thrust stand used a three-wire pendulum to suspend the ion thruster assembly, and a laser interferometer measured the pendulum's displacement. The other thrust stand concept employed an inverted pendulum and used a transformer and a moveable ferrous core as a displacement sensor. The pendulum thrust measurement system, ${ }^{9}$ shown in Figure 1, was used in ground tests to document the thrust correction factor $y$ for a mercury ion thruster operating in the $2 \mathrm{~kW}$ to $2.8 \mathrm{~kW}$ range. When the thruster was operated at a ratio of net accelerating voltage to total extraction voltage of 0.82 , a discharge voltage of $37 \mathrm{~V}$, and discharge losses of $220 \mathrm{eV} / \mathrm{ion}$, the value of $\gamma$ was reported to be 0.93 to 0.94 . Beam probe data indicated the beam divergence thrust factors were about 0.98 . Using Equation (3), the value of the charge-state thrust correction factor, $\alpha$, was found to be between 0.95 and 0.96 . These beam probe tests also verified the circular symmetry of the ion beam since the values of $F_{\mathrm{T}}$ obtained with a traversing probe rake were in agreement with values obtained with a stationary rake assuming circular symmetry.

The computed in-space ideal thrust levels of the SERT II mercury ion engines No. 1 and No. 2 were $28.5 \mathrm{mN}$ and $28.7 \mathrm{mN}$, respectively. ${ }^{13}$ Ground-based ion beam current density profile data were obtained, ${ }^{14}$ and these data were fitted to a two-parameter equation describing the ion current density at all locations in the plume. ${ }^{15}$ Using computational methods described in Reference 15 , a value of $F_{T}=0.96$ was obtained for the SERT II thrusters operating at the nominal 28 $\mathrm{mN}$ thrust level. In the calculation of $F_{T}$, it was assumed that the ion velocity was constant for any trajectory in the plume, and that the probable errors associated with the assumption of singly charged ions were less than those of the electrical parameters used in the thrust calculation.' Since there were no ground-based direct thrust measurements of the SERT II thrusters, the value of $\alpha$ was determined to be 0.97 to 0.98 based on mass-spectrometer charge-state measurements using a $15 \mathrm{~cm}$ dianteter mercury ion thruster operating at the nominal SERT II thruster condition which had a discharge voltage of $37 \mathrm{~V}$ and a discharge chamber propellant utilization efficiency of $\approx 80 \%{ }^{16}$ The thrust correction factors reduced the ideal in-space thrust values by $6 \%$ to $7 \%$. Uncertainties in telemetered electrical parameters and groundbased thrust correction factors produced an estimated $2.2 \%$ uncertainty in the calculated thrust. ${ }^{13}$

A pendulum thrust balance was used to measure the ground-based thrust of an ETS III engineering model thruster. ${ }^{\text {II }}$ The indicated value of the thrust correction factor, $\gamma$, was 0.91 at the nominal ETS III thruster operating conditions. The ideal in-space thrust levels of the two ETS III ion thrusters, determined from telemetered values of $\mathrm{J}_{\mathrm{B}}$ and $\mathrm{V}_{\mathrm{B}},{ }^{5}$ were $1.93 \mathrm{mN}$ and $2.05 \mathrm{mN}$, respectively. Ground-based measurements of $y$ were used to correct the ideal thrust values to $1.76 \mathrm{mN}$ and $1.87 \mathrm{mN}$, respectively.

Using modem, sophisticated thrust-stands, ${ }^{10}$ measurements of the thrust and charge-state thrust correction factors can be obtained more accurately than those that rely on mass spectrometer data as was done with the SERT II data. High fidelity information on charge-state effects can be obtained from groundbased probe rake measurements of $F_{T}$ which can then be used to determine $\alpha$ by employing Equation (3).

Thrust Measurements From Accelerometers. Direct measurements of the in-flight thrust of electric propulsion devices require very sensitive, space qualified accelerometers whose sensitivities may have to be as low as a few tens of ng's. This requirement is derived from the low thrust levels ( 10 's of $\mathrm{mN}$ ) of ion thrusters, and the relatively high spacecraft mass which in many cases will exceed one metric ton. Accelerometer-based thrust measurements were best documented during the flight of the $28 \mathrm{mN}$ SERT II mercury ion thrusters. ${ }^{4,13}$ The SERT II Miniature Electrostatic Accelerometer (MESA) had a proof mass which was suspended normal to the accelerometer sensitive axis by electrostatic forces produced by voltage pulses. The pulse frequency was proportional to the external acceleration. ${ }^{13}$ The full-scale measurement was $100 \mu \mathrm{g}$. The instrument was calibrated first by obtaining a null-reading with the MESA sensitive axis perpendicular to the Earth's gravitational vector. and then "micro-g" calibrations were made by inclining the accelerometer axis to full-scale angles of

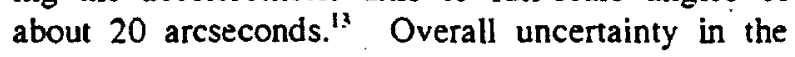
acceleration measurement was estimated to be $\pm 1 \%$. 
The SERT II accelerometer was located $2.39 \mathrm{~m}$ from the spacecraft center-of-mass as shown in Figure 3. The thrust vector was canted 10 degrees relative to the MESA sensitive axis. The measured acceleration resulted from a combination of a component of the thrust vector, a gravity gradient component, and a centripetal acceleration due to the MESA revolving around the spacecraft center-of-mass once per orbit. ${ }^{1 .}$ The measured acceleration can be expressed as:

$$
a=\left(\frac{1}{M_{S C}} F \cos \phi+d \omega^{2}+\frac{2 \mu d}{r^{3}}\right) \frac{1}{g}(4)
$$

The orbital accelerations, indicated by the second and third terms of Equation (4), were determined to be $0.73 \mu \mathrm{g}$ 's. At the SERT Il altitude of $\sim 1000 \mathrm{~km}$, acceleration due to atmospheric drag was estimated to be two orders of magnitude less than the sum of the second and third terms of Equation (9)..$^{13}$ With an expected maximum thrust of about $28 \mathrm{mN}$, a cant angle of 10 degrees, and a spacecraft mass of 1524 $\mathrm{kg}$, the thrust-produced acceleration was expected to be approximately $1.8 \mu \mathrm{g}$ 's. The MESA-derived thrust value of $27.4 \mathrm{mN}$ for SERT II Thruster No. I was within $3 \%$ of the value $(26.8 \mathrm{mN})$ determined from telemetered data and ground calibrations. Results of the two thrust measurement techniques, including probable errors, are shown in Figure 4. The thrust level determined from electrical parameters would likely have a smaller estimated error and would be nearly as accurate as the accelerometer measurements of thrust if modem thrust stands and beam diagnostic methods had been used to provide high fidelity values of the thrust correction factor $\gamma$. Extremely accurate measurements of in-flight thrust can be obtained using the acceleration measurement technique. If the methodology described in Reference 13 is followed, the probable error in thrust using the MESA was estimated to be $\pm 1 \%$.

Discussions of MESA null-bias and small orbital variations, with and without applied thrust, can be found in Reference 13. Reference 17 describes the detailed characteristics of a miniature electrostatic accelerometer similar to the MESA employed in the SERT II. This new device has a mass of $2.2 \mathrm{~kg}$ and a power requirement of $-9 \mathrm{~W}$.

More recently, a Space Acceleration Measurement System (SAMS) was developed to measure the micro- gravity environment for experiments flown aboard the Shuttle Orbiter. ${ }^{1 *}$ SAMS was designed to measure the low-gravity acceleration vector's three orthogonal components. Each acceleration axis sensor has a programmable multi-gain amplifier which provides an auto-ranging capability and sensitivities of $1 \mu \mathrm{g}$ or 10 ng depending upon the sensor model selected. The basic unit contains 3-triaxial heads that can be located at various sites. The mission data provide acceleration, time, temperature, and electronic zero calibration. The rack-mounted version of SAMS for experiments in the Spacelab module of the Orbiter weighs $31 \mathrm{~kg}$ and has a volume of about $0.06 \mathrm{~m}^{3}$. A simplified derivative of the SAMS might be considered for the thrust measurements aboard spacecraft using electric propulsion.

Thrust Measurements From Changes in Orbit Radius. - The thrust levels of both SERT II thrusters and one ETS III ion thruster were determined by measuring the changes in orbit radius after extended periods of operation. ${ }^{\text {ts }}$ If $F_{\text {TAN }}$ is the component of thrust tangent to the orbit of the spacecraft and directed to raise the orbit, the value of $F_{\text {TAN }}$ is:

$$
F_{T A N}=\frac{M_{S C} \mu^{1 / 2}}{\Delta t}\left(r_{0}^{-1 / 2}-r^{-1 / 2}\right) \text {. }
$$

The beginning-of-life SERT II spacecraft mass was $1524 \mathrm{~kg}$. If the orbit change is small relative to the initial orbit, then

$$
r-r_{0} \approx \frac{2 r_{0} F_{T A N}(\Delta t)}{M_{S C}}\left(\frac{r_{0}}{\mu}\right)^{1 / 2} .(6)
$$

As shown in Figure 3, the value of $F_{\text {TAN }}$ for the SERT II ion thruster was:

$$
F_{\text {TAN }}=F \sin \phi \text {. }
$$


The thrust values were determined over an extended period of time because the estimated accuracy of the radius measurement was $\pm 300 \mathrm{~m}^{1 . "}$ Since the measured change in altitude of the spacecraft was $20 \mathrm{~km}$ after 34 days of thrusting, and the initial orbit radius, $r_{n}$, was $7400 \mathrm{~km}$, the tangential thrust was determined to be $4.9 \mathrm{mN}$. Since the angle, $\phi$, was 10 degrees, the thrust obtained from Equation (7) was $28 \mathrm{mN}$. The thrust obtained from the orbit change measurements was $3.7 \%$ to $4.5 \%$ higher than measurements using telemetered electrical parameters and a $\gamma=0.94$. Results of the three thrust measurement techniques are shown in Figure 4. Probable error using the orbitchanging method was estimated to be $\pm 5 \% .^{13}$

The ETS III spacecraft mass was $382 \mathrm{~kg}$ and the initial orbit radius was $7470 \mathrm{~km}^{5}$ Although there were two thrusters on-board, only one operated at a time due to power limitations. The spacecraft orbit was raised about $5.7 \mathrm{~km}$ after $110 \mathrm{~h}$ of thrusting using Ion Thruster No. 2. Orbit raising was due to the 2 $\mathrm{mN}$ ion thruster and also reaction control thrusters which unloaded a reaction wheel used to counter ion thruster produced torques. After accounting for the impulse produced by the reaction control thrusters, the thrust of the ion thruster was determined to be 2.05 $\mathrm{mN}$ which was about $9.6 \%$ higher than the values obtained from telemetered electrical parameters using a $y=0.91 . "$ The thrust stand measurements at the nominal ETS III thruster conditions indicated a correction factor, $y$, of 0.91 which implies the true thrust of Thruster No. 2 was about $1.87 \mathrm{mN}$.

Possible errors in thrust derived from orbit radius change of either the SERT II or the ETS III spacecraft include non-circular orbits, uncertainty in $\mathrm{M}_{\mathrm{SC}}$, misalignment of reaction control thrusters, ion engine thrust variations, and unexpected periodical variations in spacecraft yaw attitude angle., These results indicate that the orbit-changing determination of the ion engine thrust level is not as accurate as the accelerometer method.

Thrust Measurements From Reaction Wheel Speed Diagnostics. - The ETS III ion thrusters produced a torque about the spacecraft pitch axis." The torques produced by the ion thruster and other external disturbances were compensated for using a reaction wheel. The reaction wheel saturated after about 30 minutes and had to be unloaded by hydrazine reaction control thrusters. It was found that if the thrust was evaluated at the same phase of spacecraft revolution about the Earth. the effect of external disturbance torques on wheel speed could be minimized to $-2 \%$ of the maximum reaction wheel speed. Ignoring the external disturbances, the thrust' can be simply derived from:

$$
\frac{d}{d t}\left(I_{y y} \omega_{y}\right)=F I
$$

where the left-hand-side of the equation is the rate of change of spacecraft angular momentum which is compensated by the pitch axis reaction wheel. Figure 5 shows the thruster locations on ETS III. The rate of change of angular momentum of the wheel is related to the thrust by:

$$
F X I=\frac{I_{R W} \omega_{M A X}(\Delta \omega)}{100(\Delta t)}
$$

The values $I_{R W}$ and 1 are known properties of the reaction wheel and spacecraft configuration, respectively. The propulsion tine was taken to be an integer number multiplied by the orbital period in order to minimize the effect of external disturbances on thrust measurement accuracy. The value of $\Delta \omega$ was obtained from reduced telemetry data where the percent of maximum reaction wheel speed $(\Delta \omega)$ was displayed versus time. Since the energy of the reaction wheel was unloaded about every 30 minutes, the wheel speed increases for each cycle were added throughout the ion thruster propulsion period. For example, the thrust was calculated based on a propulsion time of five - 107 minute revolutions and a $\Delta \omega$ of $658 \%$ which was accunulated over $\sim 19$ reaction wheel desaturation cycles. The thrust values of the ETS III Ion Thrusters No. 1 and No. 2, determined from reaction wheel speed changes, were $1.92 \mathrm{mN}$ and $1.99 \mathrm{mN}$, respectively. Corresponding values, based on in-flight electrical measurements and a y of 0.91 , were $1.76 \mathrm{mN}$ and $1.87 \mathrm{mN}$, respectively. As shown in Figure 4, thrust values determined from electrical parameters were $6.4 \%$ to $9.1 \%$ lower than those obtained from in-space reaction wheel diagnostics. Measurement uncertainties, using the reaction wheel speed method, are apparently much larger than 
those associated with the accelerometer diagnostics.

Thrust Measurements Derived From Spacecraft Spin Rate. - In 1974, four years after the launch of the SERT II spacecraft, a shallow sun angle provided marginal power to the ion propulsion system. ${ }^{4}$ The spacecraft was turned out of the orbital plane to face the sun and was spin-stabilized at $\sim 1 \mathrm{pm}$ by the back-up attitude control thrusters in order to obtain sufficient power to operate the thrusters. The spacecraft was spin stabilized about an axis defined by the spin rotation as shown in Figure 6 . The two ion thrusters could be gimballed \pm 11 degrees about the nominal thrust vector. When a thruster was gimballed, an F $\sin \theta$ component of thrust produced an angular acceleration described generally by Equation (8). The thrust can be calculated from:

$$
F=\frac{2 \pi(\Delta f) I_{S A}}{I(\Delta t) \sin \theta} .
$$

The spacecraft spin-rate was measured by analyzing pitch directions from a horizon scanner and also by the automatic gain control signal level variations from tracking station receivers., ${ }^{4,1920}$ The net frequency of rotation, $\Delta f$, was obtained after subtracting the change in rotation frequency due to natural decay from the total measured change in frequency. ${ }^{1920}$ The SERT II moment of inertia about the spin axis was $10,970 \mathrm{~kg}$ $\mathrm{m}^{2}$. All of the thrust measurements determined by spacecraft spin-rate were done with the ion thruster discharge-only operation at $80 \mathrm{~W}$. Since there was no high voltage ion extraction, there was probably significant beam divergence. The thrust derived from Equation (10) was only $-0.8 \mathrm{mN}$. The thrust level was low because $V_{B}$ was only about $37 \mathrm{~V}$, and $y$ was likely less than 0.9 because of wide angle ion trajectories. The component of thrust, F $\sin \theta$, that produced spacecraft rotation was typically $0.15 \mathrm{mN}$. Spacecraft rotation frequencies were about 6 revolutions per hour with natural decay accounting for only $-4 \%$ of the change in frequency of rotation. Change in the spinrate was determined after three days of thruster operation. Much more rapid thrust measurements could be made with $\mathrm{kW}$-class propulsion.

\section{Thrust Vector Issues}

Gimbals have been designed for many ion propulsion applications to insure on-orbit alignment of the thrust vector with the spacecraft center-of-mass. ${ }^{21-2.3}$ The alignment of each of the SERT II ion thrusters was selected so that the thrust vector would pass through the spacecraft center-of-mass. ${ }^{+}$Each thruster had a two-axis gimbal system to insure adjustment of the thrust vector if needed. ${ }^{21}$ The gimbal was designed to reposition the thrust vector by about \pm 11 degrees within a cone angle centered about a line through the thruster centerline. The gimbal system contained inner and outer gimbal rings, two actuators, and pin pullers. The inner ring was used to support the thruster and mercury propellant tanks. If there was a 2 degree or greater thrust vector misalignment from the center-of-mass, the attitude control system would not be able to counter such a disturbance torque uniess the gimbal system was exercised. Without gimbals the thrust vector could become offset because of thruster therma $/$ mechanical misalignment, spacecraft center-of-mass uncertainties and variations, or ion extraction grid misalignment. Because of these concems, the first start of a SERT II thruster was performed at $\sim 40 \%$ of the full-thrust level to insure thrust vector corrections could be accomplished by the gimbal system. The thruster was started at about 11 $\mathrm{mN}$ thrust, then increased to $22 \mathrm{mN}$, finally to the full-thrust level of $28 \mathrm{mN}$. Gimbal system adjustments were not needed at any of the three initial operating conditions or at any time during the course of $-34,000 \mathrm{~h}$ of thruster operation with ion extraction or with discharge-only operation. ${ }^{+}$The SERT II backup attitude control system was never needed to correct spacecraft attitude errors resulting from ion engine thrust vector misalignment. These results indicate that ion thruster alignment, spacecraft centerof-mass uncertainties, and ion optics vectoring are issues that can be readily addressed such that virtually no attitude control adjustments are needed to correct thrust vector misalignments.

Thrust vector misalignment can also be measured in ground tests by using moveable ion beam probes or probe rakes. ${ }^{9,12,24}$ One such system employed twenty three $1.27 \mathrm{~cm}$ diameter planar probes spaced $15.2 \mathrm{~cm}$ apart., ${ }^{9.12}$ The probe rake was swept in an arc in a plane normal to the thruster centerline. The probe rake could be located at various axial locations. The probe data were processed to obtain ion current density contour plots as shown in Figure 7. Align- 
ment measurements were made to determine the location of the thruster centerline relative to the plane of the probe rake. The data of Figure 7 indicated a 0.9 degree thruster vector misalignment which resulted in a $0.01 \%$ thrust loss." Short-term beam probe rake diagnostics could easily be implemented to determine the thrust vector during spacecraft integration or flight qualification tests.

At the University of Giessen, a $1.8 \mathrm{~m}$ long ion beam probe boom has been developed to provide current density profiles and beam divergence diagnostics which allow calculation of divergence thrust correction factors and thrust vector offsets. ${ }^{24}$ The boom was rotated about its midpoint and consisted of 90 probes which were situated in a case with a $2.2 \mathrm{~mm}$ slit. The case also had electrodes to suppress secondary electrons emitted from the probes. The probe system could take a complete set of data, when rotated through 180 degrees, in about $30 \mathrm{~s}$. Alignment of the thruster axis relative to the center of the boom was accomplished using a laser mounted on the boom and a set of mirrors. Ion beam profiles were taken at 2.5 m downstream of a $10 \mathrm{~cm}$ diameter xenon radiofrequency ion thruster. A three-dimensional display of the ion current density profile is shown in Figure 8. From these data constant current density profiles were displayed to determine beam divergence and thrust vector details. Data taken using the $580 \mathrm{~W}, 15$ $\mathrm{mN}$ thruster revealed a thrust vector deviation up to 0.6 degrees during the first 20 minutes of operation. ${ }^{24}$ After the warm-up phase, there was no further offset of the thrust vector. The 0.6 degree thrust vector offset was within the spacecraft manufacturer's specifications. ${ }^{24}$

\section{Inert-Gas Propellant Flow Rate Measurements}

A significant number of xenon feed systems have been developed for either plasma contactors ${ }^{25,26}$ or ion thrusters. ${ }^{2327-31}$ The main requirement for these systems was for flow control, but flow rate can be readily measured by monitoring pressures upstream of precalibrated flow restrictors which are used in most of the systems. A brief description on the selection of commercial flow restrictors is given in Reference 32. The ETS VI flight system, composed of four xenon ion thrusters for spacecraft North-South stationkeeping and scheduled for launch in 1994, employs thermal-mechanical flow controllers and sensors where the flow rate is proportional to the difference in resistance of two heated wire coils wound on a capillary tube. ${ }^{* 0}$ This concept has been extensively used. at atmospheric pressure, in ground-based flow measurements. ${ }^{14}, 4$ In addition to the thermal-mechanical flow controller, three other flow control systems will be described. Flow system schematics are shown in Figures 9a through 9d. A large data-base of flight qualified feed system components for a wide range of propellants can be found in References 35 and 36 .

The plasma contactor flow control system ${ }^{26}$ shown in Figure 9a consists of a pressure regulator which reduces the pressure upstream of a flow restrictor to $\sim 67 \mathrm{kPa}$. The nominal xenon flow rate was $50 \mu \mathrm{g} / \mathrm{s}$. A pressure transducer was located downstream of the flow restrictor simply to indicate whether the downstream valve was open or closed. This transducer could have been located upstream of the flow restrictor to effectively monitor the flow rate through the critical orifice. A system similar to this one, employing a pressure regulator, was recently flown on the Atmospheric Laboratory for Applications of Science aboard the Shuttle Orbiter. ${ }^{25}$ A flight flow control system using a pressure regulator also has been proposed for xenon ion thruster systems. ${ }^{37.38}$

The Radio-Frequency Ion Thruster (RIT) flow control system shown in Figure $9 \mathrm{~b}$ uses a pressure switch and valve to maintain the pressure in the downstream plenum within a given dead-band. ${ }^{27}$ The line pressure upstream of the pressure switch-valve assembly was about $15 \mathrm{MPa} .^{23}$ The upstream flow restrictor was designed to tailor the plenum fill-rate. The flow rates can be determined from calibration of the flow restrictors over a range of plenum pressures. A feed system similar to the one described in Figure $9 \mathrm{~b}$ was flown on the European Retrievable Carrier which is a free-flying platform that was released from the Shuttle Orbiter. ${ }^{27}$

A flow control system, shown in Figure 9c, is being developed for the UK-10, a $10 \mathrm{~cm}$ diameter ion thruster. ${ }^{28}$ The feed system concept is similar to the RIT system described in Figure 9b. The major difference is that the cathodes have start-valves which provide a high pressure pulse to assist initiation of the discharge. Flow rate calibrations can be made based on the plenum pressure measurement upstream of the flow restrictor.

Figure 9d is a schematic of the flow control system for the ETS VI ion thrusters: ${ }^{10}$ A pressure switchvalve system is used to control the pressure upstream 
of a thermal-mechanical flow controller. The flow control concept uses an orifice actuator which provides valve aperture control by thermally expanding or contracting the valve stem length. This concept has been employed in many commercial flow meters." Flow rate calibrations were made by detecting the difference in resistance of two heated wire coils wound at two location on a capillary tube. If the two coils were identical, a no-flow situation would produce no difference in the resistance of the coils. With flow the temperature and resistance of the coils were different because of coil heat transfer to the gas stream. The difference in coil resistance can be calibrated against propellant flow rates. The mass flow controller has successfully completed launch vibration simulations and thermal vacuum tests, and it is now undergoing steady-state and cyclic life tests.

Over long periods of time, average mass flow rates for inert-gas propellants can also be determined by monitoring the pressure and temperature of the propellant tank."3 Using the gas equation-of-state, decreases in propellant delivery pressure with time can be used to calculate an average flow rate. These data can be checked for consistency by knowing the initial propellant mass and initial tank pressure and monitoring the propellant used. The propellant monitoring simply involves using the measured flow rates and operating times to calculate a predicted tank pressure variation.

Vacuum Facility Impacts on Pre-flight Calibrations

High vacuum facility pressure, due primarily to thruster propellant, can impact the electrical, performance, and diagnostic measurements of ion thrusters. Ion thruster mass flow rate and ion beam divergence measurements may have some uncertainty if the facility background pressure is in excess of $2 \mathrm{mPa} .^{10-12}$ Some propellant can be ingested from the facility into the discharge chamber of the ion thruster. The ingested flow rate can be estimated from:

$$
\dot{m}_{I}=\frac{A_{G} K P_{F}}{4}\left(\frac{8 M}{\pi k T_{M} N_{A}}\right)^{1 / 2}
$$

For a typical $30 \mathrm{~cm}$ diameter xenon ion thruster the ingested flow rate would be:

$$
\dot{m}_{I}=4.1 \times 10^{-5} P_{F}, \mathrm{~kg} / \mathrm{s}
$$

In this case the ingested flow rate is about $1 \%$ of the input flow rate of a $5 \mathrm{~kW}$ xenon ion thruster tested at a pressure of $1.3 \mathrm{mPa}$. In order to adequately estimate ingested flow rates, it is important to obtain a local pressure measurement in the vicinity of the thruster, but the location and methodology should be chosen to minimize the impact of charged particles on the accuracy of the pressure sensor. Vacuum facility pressures less than $2 \mathrm{mPa}$ will likely be required for all thruster life tests and flight qualification tests to ensure high fidelity performance calibrations. More detailed descriptions of test facility environmental effects on thruster operating conditions and lifetime can be found in References 41 and 43 .

Care must be taken in the diagnostics of ion beam divergence if the vacuum facility pressure is in excess of $1 \mathrm{mPa}{ }^{43}$ The high velocity xenon ions can undergo charge-exchange reactions with slow xenon atoms. This process reduces the magnitude of downstream ion beam probe measurements. For example, it was estimated that $50 \%$ to $70 \%$ of the energetic beam ions of a $1500 \mathrm{eV}$ xenon ion beam had transferred charge to slow neutrals over a distance of $9.4 \mathrm{~m}$ when the background pressure was $1.7 \mathrm{mPa}^{41,43}$ Even at a location only $0.5 \mathrm{~m}$ from the thruster it was estimated that $6 \%$ of the ion beam had undergone a chargeexchange reaction. High speed helium cryopumping capabilities $^{41}$ may be required to insure accurate farfield plume diagnostics.

Another phenomenon that can affect ion thruster ground-based performance measurements is the deposition of insulating films on the the discharge chamber anode. Such films have been observed to cause an increase in discharge voltage with time. The major source of such electrode contamination was from poorly baffled oil diffusion pumps that did not effectively inhibit oil backstreaming." If any of the pump baffles were not refrigerated to temperatures less than -70 .degrees Celsius, there was some risk that insulating films would form on critical electrodes. Obviously this environment would be unsuitable for spacecraft integration and qualification tests. Most of 
the vacuum facility induced effects on thruster performance measurements could be countered by using helium cryopumps and possibly conductance limiters to reduce the pressure in the vicinity of the ion thruster to less than about $0.7 \mathrm{mPa}$.

\section{Concluding Remarks}

In-flight measurements of ion engine thrust and mass flow rates were reviewed. Flight experiments have shown that accelerometers provided the most accurate in-flight thrust measurements with uncertainties of about $\pm 1 \%$. Calculated thrust values can be determined from telemetered data and the beam divergence/charge-state thrust factor which has to be obtained from ground test calibrations. Orbit change measurements, reaction wheel diagnostics, and spacecraft rotation rate measurements have also been used to determine thrust albeit with larger measurement uncertainties than obtained with accelerometers. Disturbance torques, caused by thrust components as low as $0.15 \mathrm{mN}$, were used to produce measurable changes in spacecraft rotation rates or reaction wheel speeds. These methods were used to infer thrust levels. During the SERT II flight experiment it was found that pre-flight alignment of the thrust vector was adequate, and no gimbal system adjustments or use of the backup attitude control system were required over the mission to counter disturbance torques produced by thrust vector misalignment.

All of the inert-gas propellant metering systems flown to date rely on pre-calibrated critical orifices to quantify mass flow rates. Most recent experiences are from flights of plasma contactors and the flight of the radio-frequency ion thruster on a platform released from the Shuttle Orbiter. A thermal-mechanical flow control and metering system is being developed for the ETS VI ion thruster system. The ETS Vl system uses heated coils wound on a capillary flow tube, and the flow rate is determined from differences in coil resistances. This concept is routinely used in groundbased mass flow measurements. If care is taken in ground-based calibrations, and an accelerometer is used, very accurate in-flight measurements of thrust and mass flow rate should become a routine process.

\section{References}

'Sovey, J. S.. et al., "The Evolutionary Development of High Specific Impulse Electric Thruster Technology," AlAA Paper 92-1556, March 1992.
2 Pollard, J. E., et al.. "Electric Propulsion Flight Experiences and Technology Readiness." AIAA Paper 93-2221. June 1993.

'Sovey, J. S., Carney, L. M., and Knowles, S. C., "Electromagnetic Emission Experiences Using Electric Propulsion Systems," J. of Propulsion and Power. Vol. 5, No. 5, September-October 1989, pp. 534-547.

${ }^{4}$ Kerslake, W. R. and Ignaczak, L. R., "Development and Flight History of the SERT II Spacecraft," AIAA Paper 92-3516, July 1992.

"Azuma, H., et al., "Thrust Evaluation of $5 \mathrm{~cm}$ Ion Thruster on Engineering Test Satellite III," Proceedings of the JSASS/AlAASDGLR 17th International Electric Propulsion Conference, 1984, pp. 130-135.

${ }^{6}$ Worlock. R. M., et al., "The Cesium Bombardment Engine North-South Stationkeeping Experiment on ATS 6," AIAA Paper 75-363, March 1975.

7 Byers, D. C., "Electron Bombardment Thruster Field and Particle Interfaces," J. of Spacecraft and Rockets, Vol. 16, September-October 1979, pp. 289 . 301.

Deininger, W. D., "Electric Propulsion Produced Environments and Possible Interactions with the SP100 Power System," AIAA Paper 85-2046, September 1985.

'Banks, B. A., et al., "Direct Thrust Measurement of a 30-cm Ion Thruster," NASA TMX-71646, March 1975.

${ }^{10}$ Haag, T. W. and Curran, F. M., "Arcjet Starting Reliability: A Multistart Test on Hydrogen and Nitrogen Mixtures," AIAA Paper 87-1061, May 1987.

"Kitamura, S., "Report on the Development of the Engineering Test Satellite-III (ETS-III) Ion Engine System," NASA Translation, NASA TM-77538, July 1984.

${ }^{12}$ Danilowicz, R. L., et al., "Measurement of Beam Divergence of 30-Centimeter Dished Grids," AIAA Paper 73-1051, October 1973.

1." Kerslake, W. R., Goldman, R. G., and Nieberding. W. C., "SERT II: Mission, Thruster Performance, and In-Flight Thrust Measurements, J. of Spacecraft and Ruckets, Vol. 8, No. 3, March 1971, pp. 213-224.

is Byers, D. C., "Angular Distribution of Kaufman Ion Thruster Beams," NASA TND-5844. June 1970.

15" Reynolds, T. W., "Mathematical Representation of Current Density Profiles From Ion Thrusters, "NASA TND-6334, April 1971.

${ }^{16}$ Milder, N. L., "Comparative Measurements of Singly and Doubly Ionized Mercury Produced by Electron-Bombardment Ion Engine," NASA TND1219 , July 1962. 
17 Anon., "Microgravity Measurement With the Miniature Electrostatic Accelerometer," Canopus Systems, Inc. Specification, Ann Arbor, MI, May 1993.

${ }^{18}$ DeLombard, R. and Finley, B. D., "Space Acceleration Measurement System Description and Operations," NASA TM-105301, November 1991.

${ }^{19}$ Kerslake, W. R. and Ignaczak. L. R., "SERT II 1979 Extended Flight Thruster System Performance," AIAA Paper 79-2063, October 1979.

2o Kerslake, W. R., "SERT II Thrusters - Still Ticking After Eleven Years," AIAA Paper 81-1539, July 1981.

"Zavesky, R. J. and Hurst, E. B., "SERT Il Gimbal System," NASA TMX-2427, 1971.

22 Anon., "30-Centimeter Ion Thrust Subsystem Design Manual," NASA TM-79191, June 1979.

${ }^{23}$ Bassner, H., et al., "Ion Propulsion Package (IPP) for N/S Stationkeeping of the ARTEMIS Satellite," Proceedings of the AIDAA/AIAA/DGLR/JSASS 22nd International Electric Propulsion Conference, IEPC Paper 91-055, October 1991.

${ }^{24}$ Groh, K. H., et al., "Beam Diagnostics for the Characterization of Ion Thruster Beam Parameters," Proceedings of the AIDAAAIAADGLRJSASS 22nd International Electric Propulsion Conference, IEPC Paper 91-083, October 1991.

${ }_{25}$ Beattie, J. R., et al., "System Performance of ATLAS Plasma Contactor," AIAA Paper 90-2568, July 1990.

${ }^{26}$ Robson, R. R., et al., "Plasma Contactor for the ISTP/Polar Spacecraft," Proceedings of the AIDAAV ALA1DGLRJSASS 22nd International Electric Propulsion Conference, IEPC Paper 91-064, October 1991.

${ }^{27}$ Bassner, H., Berg, H.-P., and Kukies, R., "RITA Development and Fabrication for the ARTEMIS Satellite," Proceedings of the AIDALALAADGLR JSASS 22nd International Electric Propulsion Conference, JEPC Paper 91-057, October 1991.

${ }^{28}$ Feam, D. G., "The UK-10 Ion Propulsion System A Technology for lmproving the Cost-Effectiveness of Communications Spacecraft," Proceedings of the AIDAA/AIAADGLRJSASS 22nd International Electric Propulsion Conference, IEPC Paper 91-009, October 1991.

${ }^{24}$ Feam, D. G., Martin, A. R., and Smith. P., "Ion Propulsion Research and Development in the UK," IAF Paper 89-274, presented at the 40th Congress of the International Astronautical Federation, Malaga, Spain, October 1989.
3. Shimada, S., et al., "Mass Flow Controller of Ion Engine System," Proceedings of the AIDALAALA.V DGLRJSASS 22nd International Electric Propulsion Conference, IEPC Paper 91-109, October 1991.

"Shimada, S., et al., "Ion Engine System Development of ETS VI." Proceedings of the AID.AA/AIA.A DGLR/SSASS 22nd International Eleciric Propulsion Conference, IEPC Paper 91-145, October 1991.

${ }^{32}$ Wallace, N. C., "A Flight Test of the Alleviation of Spacecraft Charging Using a UK-10 Ion Thruster Cathode," Proceedings of the AID.LA/AILLADGLR JSASS 22nd International Electric Propulsion Conference, IEPC Paper 91-063, October 1991.

${ }_{33}^{33}$ Brophy, J. R. and Garner, C. E., "A 5000 Hour Xenon Hollow Cathode Life Test," AIAA Paper 912122, June 1991.

${ }^{34}$ Pless, L. C., "Vacuum Rated Flow Controllers for Inert Gas Ion Engines," AIAA Paper 87-1078, May 1987.

35 Bader, C. H., "Potential Propellant Storage and Feed Systems for Space Station Resistojet Propulsion Options," NASA CR-179457, January 1987.

.6 Bader, C. H., "Component Data Base for Space Station Resistojet Auxiliary Propulsion," NASA CR180834, January 1988.

${ }^{37}$ Beattie, J. R., Mattosian, J. N., and Robson, R. R., "Status of Xenon Ion Propulsion Technololgy," AJAA Paper 87-1003, May 1987.

seattie, J. R., Willians, J. D., and Robson, R. R., "Flight Qualification of an 18-mN Xenon Ion Thruster," AIAA Paper 93-1085, February 1993.

${ }^{39}$ Prickett, R. P. and Hoang, J. V., "Satellite Propulsion Performance Modeling Using Flight Data," J. of Propulsion and Power, Vol. 8, No. 5, SeptemberOctober 1992, pp. 971-979.

${ }^{* 0}$ Rawlin, V. K., "Performance of Large Area Xenon Ion Thrusters for Orbit Transfer Missions," NASA TM-102049, May 1989.

"Patterson, M. J. and Verhey, T. R., "5-kW Xenon Ion Thruster Lifetest," AIAA Paper 90-2543, July 1990.

42 Sovey, J. S. and Patterson, M. J., "Ion Beam Sputtering in Electric Propulsion Facilities," AIAA Paper 91-2117, June 1991.

4 Rawlin, V. K. and Mantenieks, M. A., "Effect of Facility Background Gases on Internal Erosion of the 30-cm Hg lon Thruster," AIAA Paper 78-665, April 1978.

4 Sovey, J. S., et al., "Test Facilities for High Power Electric Propulsion," AIAA Paper 91 -3499, September 1991.

*" Patterson, M. J.. Private Communication, NASA

Lewis Research Center, Cleveland, Ohio, May 1993. 


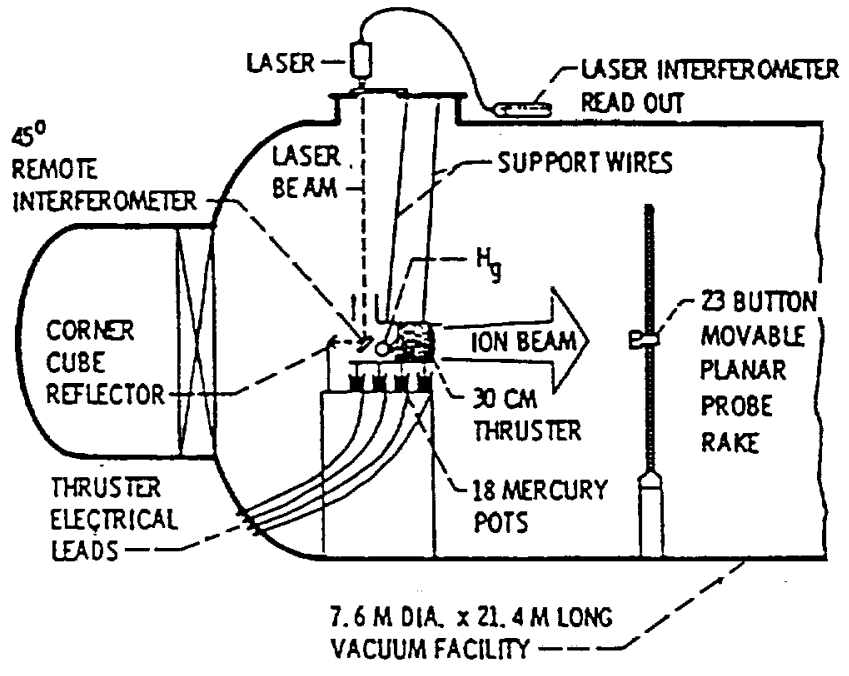

Figure 1. - Laser interferometer thrust measurement system. 9

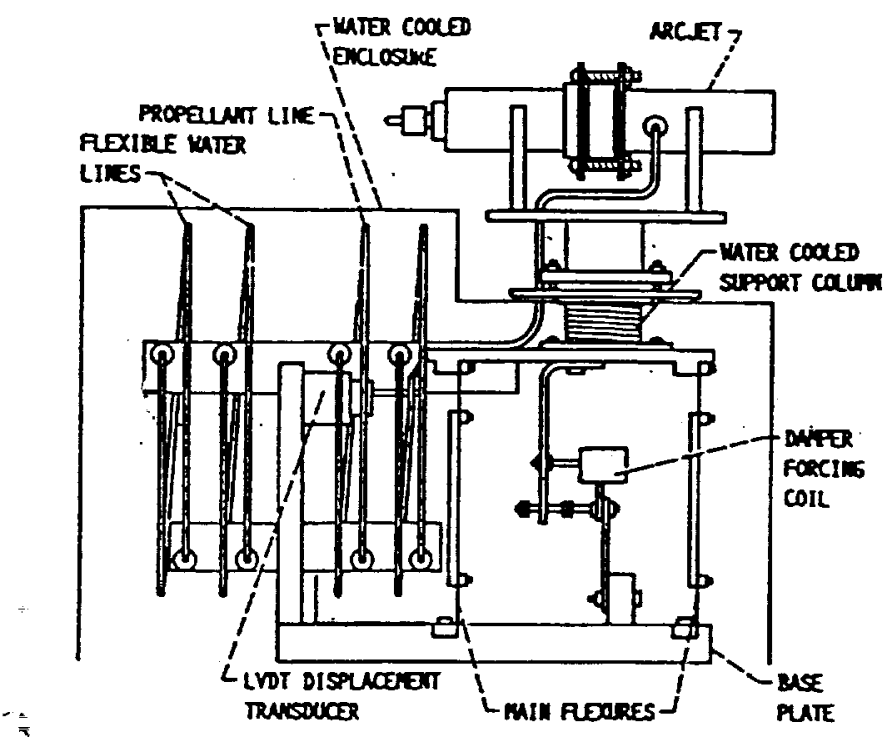

Figure 2. - Inverted pendulum thrust stand. 10

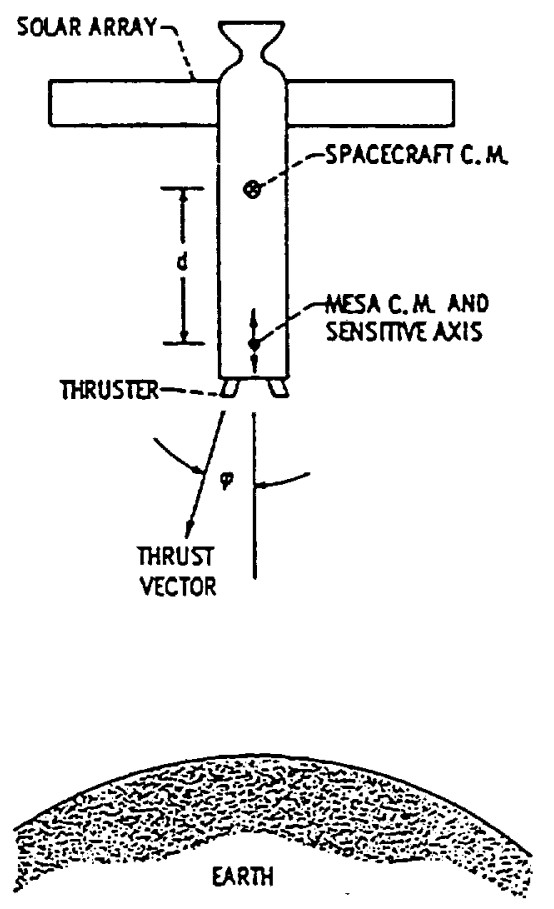

Figure 3. - SERT II acceleration measurement configuration. 13

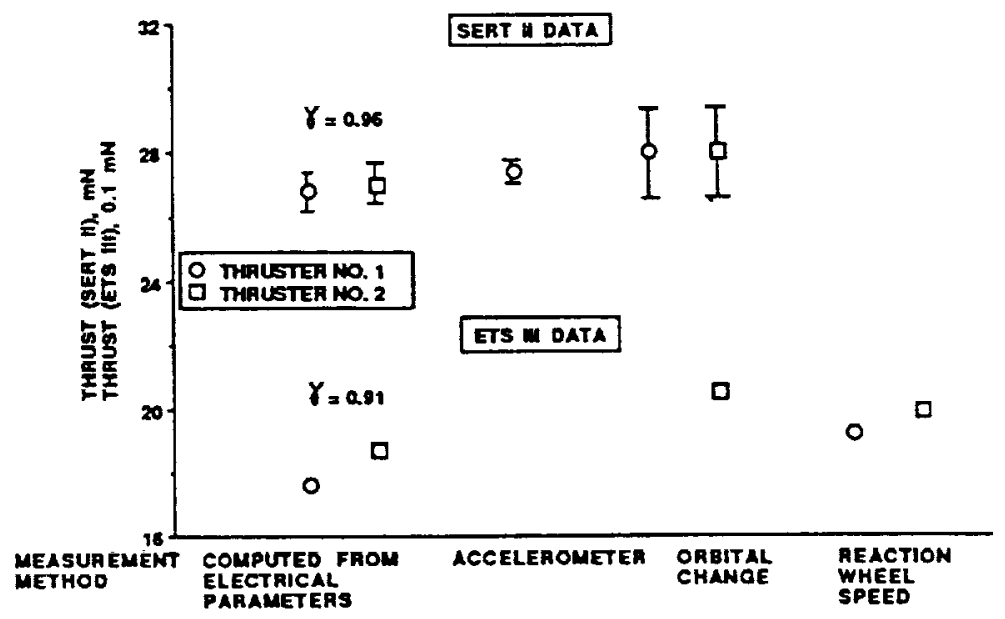

Figure 4. - In-space thrust measurements obtained from the SERT II and ETS III ion thrusters. 5,13 



Figure 5. - Ion thruster locations on ETS 11.5

Figure 7. - Ion beam profiles taken downstream of a mercury ion thruster. 9
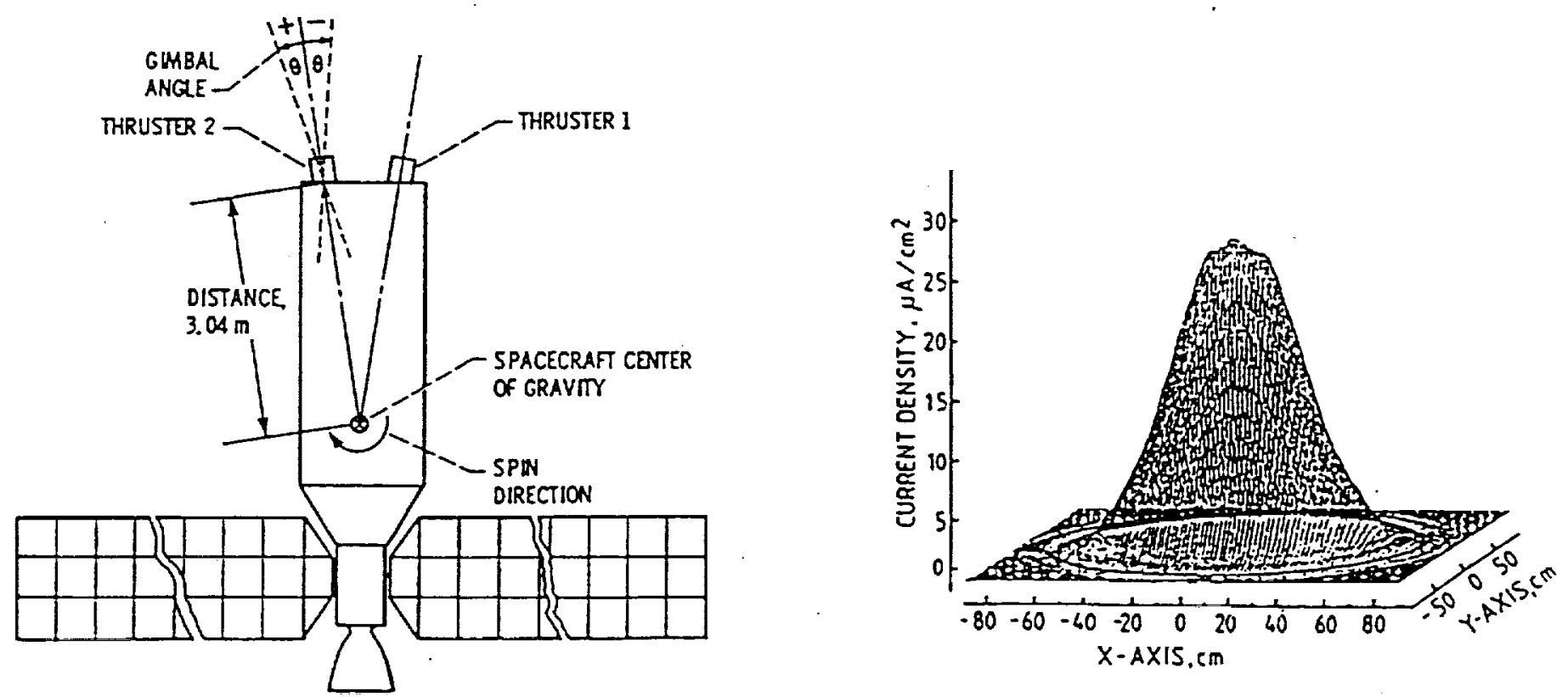

Figure 6. - SERT II spacecraft showing the ion thruster gimbal angle. 20

Figure 8. - A three-dimensional ion current density distribution $2.5 \mathrm{~m}$ from the RIT-10 xenon inn thruster. 24 


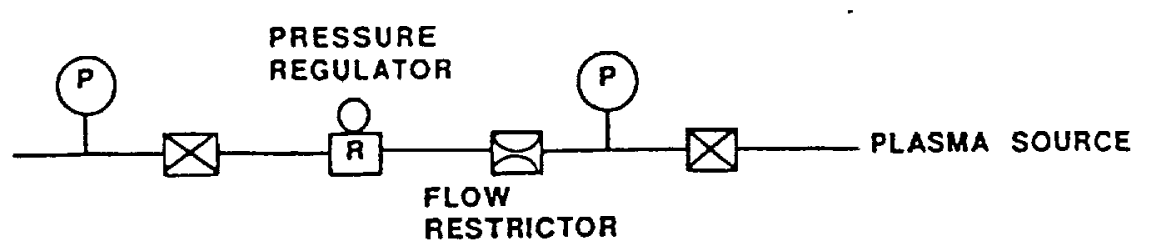

9a. Flow control for plasma contactor. 26

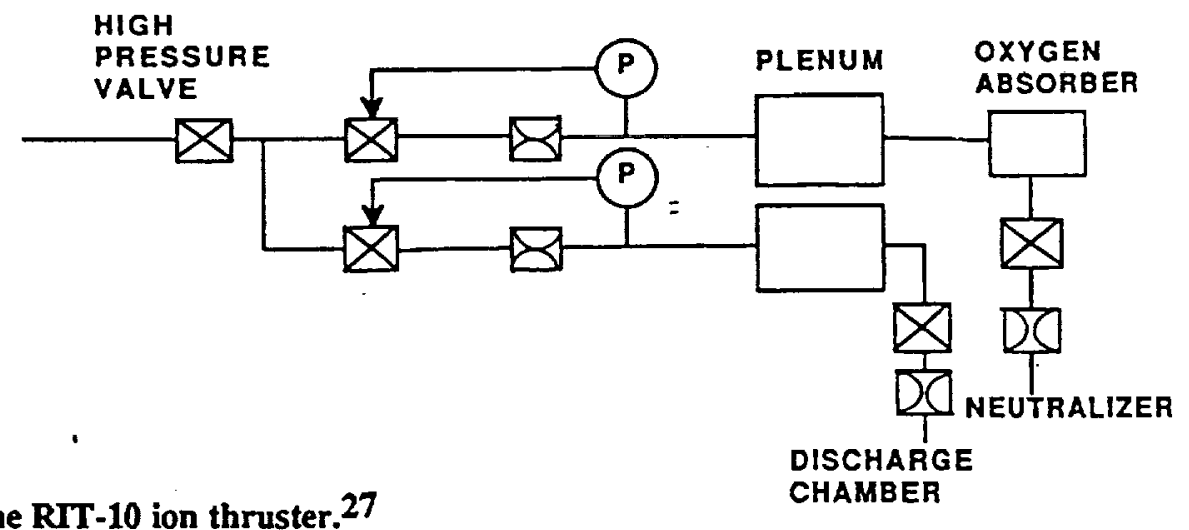

9b. - Flow control for the RIT-10 ion thruster. 27

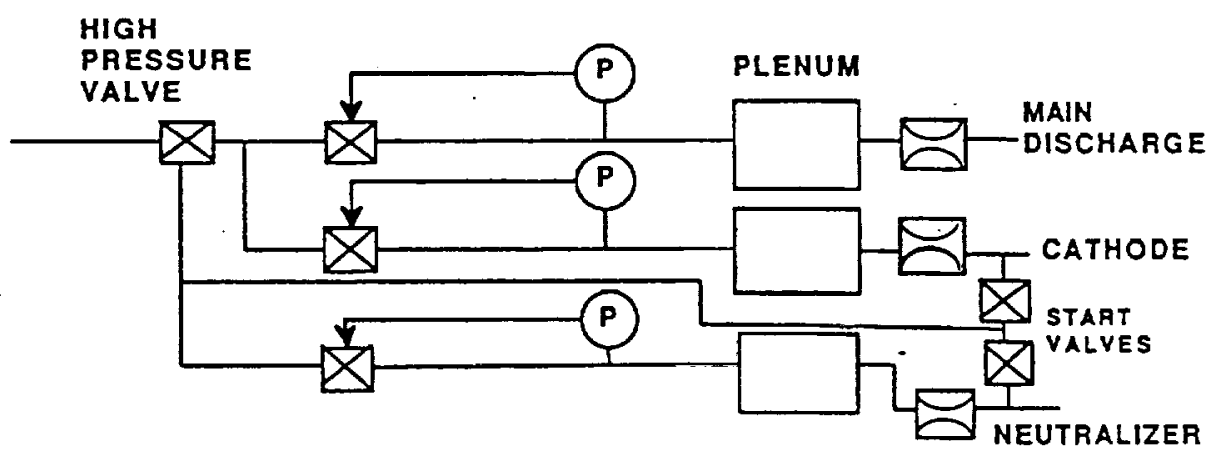

9c. - Flow control for the UK-10 ion thruster. ${ }^{28}$

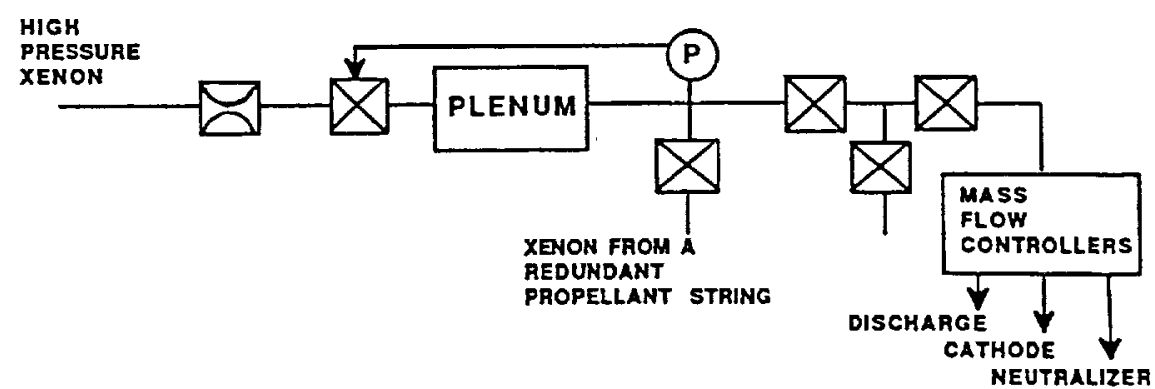

9d. - Potential flow control for the ETS-VI ion thruster. 30

Figure 9. - Xenon flow metering systems used in fight ion source and ion thruster systems. 
Public reporting burden for this collection of information is estimated to average 1 hour per response, including the time for reviewing instructions, searching existing data sources, gathering and maintaining the dats needed, and completing and reviewing the collection of information. Send comments regarding this burden estimate or any other aspect of this gathertion of intormation including sugestions for reducing this burden, to Washington Headquarters Services, Directorate for Information Operations and Reports, 1215 Jefterson Davis Hignay, Suite 1204, Artington, VA 22202-4302, and to the Office of Management and Budget, Paperwork Reduction Project (0704-0188), Washington, DC 20503.
1. AGENCY USE ONLY (Leave blank)
2. REPORT DATE
June 1993
3. REPORT TYPE AND DATES COVEAED

4. TITLE AND SUBTTILE

Characterization of In-Flight Performance of Ion Propulsion Systems

5. FUNDING NUMBERS

6. AUTHOR(S)

James S. Sovey and Vincent K. Rawlin

WU-506-42-31

7. PERFORMING ORGANIZATION NAME(S) AND ADDRESS(ES)

8. PERFORMING ORGANRATION REPORT NUMBER

National Aeronautics and Space Administration

Lewis Research Center

E-8021

Cleveland, Ohio 44135-3191

9. SPONSORING/MONITORING AGENCY NAME(S) AND ADDRESS(ES)

10. SPONSORING/MONITORING

AGENCY REPORT NUMBER

National Aeronautics and Space Administration

NASA TM-106283

Washington, D.C. 20546-0001

AIAA-93-2217

\section{SUPPLEMENTARY NOTES}

Prepared for the 29th AIAA Joint Propulsion Conference and Exhibit cosponsored by the AIAA, SAE, ASME and ASEE, Monterey, California, June 28-30, 1993. Responsible person, James S. Sovey, (216) 977-7454.

12a. DISTRIBUTION/AVAILABILITY STATEMENT

12b. DISTRIBUTION CODE

Unclassified - Unlimited

Subject Category 20

\section{ABSTRACT (Maximum 200 words)}

In-flight measurements of ion propulsion performance, ground test calibrations, and diagnostic performance measurements were reviewed. It was found that accelerometers provided the most accurate in-flight thrust measurements compared with four other methods that were surveyed. An experiment has also demonstrated that pre-flight alignment of the thrust vector was sufficiently accurate so that gimbal adjustments and use of attitude control thrusters were not required to counter disturbance torques caused by thrust vector misalignment. The effects of facility background pressure, facility enhanced charge-exchange reactions, and contamination on ground-based performance measurements are also discussed. Vacuum facility pressures for inert-gas ion thruster life tests and flight qualification tests will have to be less than $2 \mathrm{mPa}$ to ensure accurate performance measurements.

\section{SUBJECT TERMS}

Electric propulsion; Spacecraft propulsion; Propulsion; Plasma applications

15. NUMBER OF PAGES

16. PRICE CODE

$$
14
$$

\section{SECURTY CLASSIFICATION OF REPORT Unclassified}

18. SECUAITY CLASSIFICATION
OF THIS PAGE
Unclassified

19. SECUATYY CLASSIFICATION OF ABSTRACT - Unclassified 